\title{
Fusion of the Lumbar Spine: Indications and Techniques
}

\author{
Introduction by Topic Editor, Vincent C. Traynelis, M.D.
}

\section{Volume 7, Issue 6}

December 1999

This issue of Neurosurgical Focus is devoted to the indications and techniques of lumbar fusion. Interest in lumbar fusion has soared during the past few years. This is partly due to the Federal Drug Administration's downregulation of pedicle screw fixation and the emergence of new interbody fusion devices. I believe that the main reason for renewed interest in lumbar fusion, however, is fueled by the realization that many patients do not achieve adequate relief of their symptoms after surgical decompression or with conservative management.

This is truly an international issue with more than one third of the papers coming from the European community. The issue begins with two articles on posterior pedicle screw instrumentation. In the first, Arnold, et al., examine the usefulness and efficacy of variable angle screws in transpedicular fixation. La Rosa, et al., detail the use of transpedicular screw fixation and posterior fusion for adults with lumbar and lumbosacral spondylolistheses.

Stabilization is often necessary after resection of spinal neoplasms. Spinal reconstruction in patients with a good prognosis must be performed to promote fusion and long-term stability. The instrumentation techniques used in those individuals in whom only short-term survival is expected are frequently similar to those used for promotion of fusion and, therefore, there are lessons to be learned from both groups of patients. In their technical case report, Detweiler, et al., describe the complete resection of an L-5 vertebral tumor and $360^{\circ}$ reconstruction with pedicle screw fixation from L-4 to the sacrum and replacement of the vertebral body. Mühlbauer, et al., describe the use of a minimally invasive retroperitoneal approach for lumbar corpectomy and reconstruction.

The final group of papers deal with the topic of interbody fusion devices. Kettler, et al., discuss lumbar spinal biomechanics before and after implantation of several posterior cages. Barnes, et al., report on the surgical results of 35 patients who were treated with interbody cortical dowels. The patient population included individuals treated with anterior and posterior approaches. Rauzzino, et al., detail the management of 42 patients in whom anterior interbody fusions with both threaded and mesh cages were performed. McLaughlin, et al., report on the Emory experience with laparoscopic anterior lumbar interbody fusions. Finally, the very important topic of the complications of anterior lumbar spinal surgery is addressed in a comprehensive anatomical study by Samudrala, et al. 
I wish to acknowledge and thank the editorial review panel for this issue: Robert J. Hacker, M.D., Peter M. Klara, M.D., Ph.D., Noel I. Perin, M.D., Gerald E. Rodts, M.D., and Christopher I. Shaffrey, M.D. Vincent C. Traynelis, M.D. 